\title{
Rivers at the End of the End of Nature
}

\author{
Ethical Trajectories of the Anthropocene Grand Narrative
}

\author{
Celia Deane-Drummond
}

In considering the movement of the global to the local human scale and vice versa, I begin with two propositions. First, it is necessary to consider the ways in which humans tell stories or narratives about river systems. These stories impinge on the reasons for how they act; that is, they function in the sphere of morality and ethics. ${ }^{1}$ Second, the ways that humans perceive their interaction with the natural world has shifted from being understood primarily as makers of technology to that of consumers, expressed most powerfully in the consumption of water and even water systems.

Given that stories-especially histories but also scientific narratives about the environment-operate in the realm of ethics and morality, it is important to understand that ethical frameworks, generally speaking, will have some idea of a goal of human flourishing. Who defines what this goal might be is crucial. In constructing their narratives, authors often embed their own assumptions about what is right or wrong-perhaps without consciously recognizing that it shapes their stories. These narratives can creep into scientific accounts, even those that use quantitative material. I am going to probe this further by looking specifically at the philosophical assumptions buried in the concept of the Anthropocene, which started out as a geological concept but has now moved beyond this into other areas of discourse.

Water has always been significant for human societies and for religious practices in particular. And access to water that river systems provide has shaped not just the historical development of ancient settlements but also the possible type of ecological interactions between humans and other species. The particular entanglement between humans and river systems is interesting, because it provides a 
case study for reflection on the way humans envisage their specific ethical responsibilities. But rather than focus on water as such in this chapter, I am going to address primarily the idea of the Anthropocene and its ethical impact, because the theme of this project, Rivers of the Anthropocene, weaves the two together.

The Anthropocene, if we use the definition coined by Paul Crutzen, refers to the geological epoch shaped by human activities since the early Industrial Revolution (Crutzen and Stoermer 2000). According to this narrative, for the first time in human history, humans have become such a dominant force that they determine the state of the earth's crust. So if we were to fast-forward in time, their imprint would appear in the geological record. The concept of reading history through the geological record is certainly not new; even the nineteenth-century geologist David Thomas Ansted (1863) viewed his work vividly as a reading of the "great stone book of nature." The pages may be crumpled or torn, or even inverted, but the book when reconstructed tells a tale of progression and change, with increasing significance as it approaches the geological era in which we live today. The sociologist and philosopher Bronislaw Szerszynski (2012), in his discussion of the cultural significance of the Anthropocene, argues that geology is, like medicine, ideographic, dealing with ideas that stem from particulars, rather than physics, which is nomothetic and deals with general laws. In order to convey such particularities in a meaningful way, geology makes particularities observed meaningful by a reading of signs; that is, it becomes semiotic.

But for the Anthropocene, the particular way in which one might read the sign in geology is complicated by the different historical phases of human activity and action. One image of humans in a technological world is that of Homo faber, humans as maker, in which the natural world is manipulated for human purposes and ends. In the Anthropocene this becomes superseded by Homo consumens, humanity the consumer, and Homo colossus, a term coined by William Catton that signifies humans as bent on consuming exhaustible resources, including water, leading to water scarcity. The number of references to such overconsumption of river systems at the Rivers of the Anthropocene conference in 2014 was striking (Kelly this vol.), but such shifts have a profound impact on human communities as well. So Szerszynski $(2012,175)$ suggests, "If the 'bad' Anthropocene has indeed been this parody of the cycles of nature-a growth without decay, a piling up of things which are at once consumed, a technological metabolism which turns nature into commodities without replenishing nature's self-reproductive powersthen it has been not the apotheosis but the eclipse of man as Homo faber: the end of the end of nature."

But the language of the Anthropocene has still more significance, because some scholars have started to argue that humans might be able to replace the destructive habits of $H$. colossus with a new approach that self-consciously manipulates the planet in ways that are viewed as positive and have good results. According to this approach, sometimes known as eco-modernism, any uncertainties are exogenous 
factors that can be dealt with through refinement of technique, a return of $H$. faber or even perhaps $H$. melius, one who makes things better than before.

But knowledge of the earth system and even detailed analysis of one river system within the total earth system already challenges such optimism as facile and far too simplistic, encouraging a replacement of mere humanity the maker, $H$. faber with H. gubernans, the helmsperson, steering the processes of the natural world in a particular direction. The close entanglement of humans with complex river systems is another reminder that bringing back the innocuous view of $H$. faber is naive. The nature of the river system itself and the living creatures within it will dictate what may be possible for humans in that particular system, and so on to a global scale. Twenty million inhabitants have been displaced in the Gulf of Mexico following the introduction of dams (Syvitski 2014). This case shows how attempts to steer the natural world to particular human desires, Homo gubernans, have gone awry and led to unforeseen consequences.

But I want to reflect further on what happens when we consider humanity through what could be called the gaze of the Anthropocene. Now humanity becomes woven into a geological system in a way that points to the fatalistic ending of human activity that then impinges on how humans act today. In this sense the dominant narrative of the Anthropocene is brutally consequentialist. The very process depends on the perceived consequences of that activity, even though its proponents usually claim that the language of the Anthropocene is ethically "neutral" or descriptive of "facts" and so somehow removed from a moral standpoint. The Anthropocene as a way of telling the human story thereby echoes more pessimistic discourse about climate change, which also conveys apocalyptic scenarios of humanity's demise.

The social scientists Andreas Malm and Alf Hornborg (2014) add another critical voice to presumptions embedded in the Anthropocene grand narrative by arguing that it jumps far too quickly from a natural science, geology, to an assessment of the impact of the whole species, Homo sapiens, thus missing the critical and crucial, textured, social elements that are woven into human histories. They also argue that the Anthropocene makes far too many presumptions about the activities of the human species as such, so that when dealing with climate change, a fossil fuel economy, for example, is certainly not attributable to the species at large but only a small fraction of that species. As such, it is misleading in its claims for the delegation of human responsibility to the whole of the species. This ignores inequalities in contributions by different societies to change. The Rivers of the Anthropocene project, by concentrating on local as well as global impacts, avoids this difficulty to some extent, but the problem is still evident, in that the term "Anthropocene" implies that the species as a whole contributes in some way evenly to disruption of water systems.

The Anthropocene is thus a geological grand narrative that carries cultural significance beyond its immediate scientific reference and coalesces with other 
grand narratives about climate change, pointing to the entangled fate of ecological systems, human beings, and river systems. The Anthropocene, with its specter of the ultimate end of humanity, can lead to very diverse ethical responses, from resignation through to revolutionary political action. These diverse ethical responses echo alternative narratives about the way humanity is connected with the natural world, either envisioning humanity as one species among many biota, such as in Lovelock's (1987) Gaia hypothesis, or humanity in a privileged position over and against the natural world, bolstered by the promise of new technologies. The difference between narrative and drama is important, because narrative rhetoric will, arguably, have different outcomes both ethically and politically from dramatic rhetoric (Deane-Drummond 2010).

What is meant by the term "narrative" and its particular function in religious terms is very diverse. I bring in religion at this juncture, as I believe that religion has a powerful influence in shaping both morality and ethics. In religious views, ethics more often than not take the form of a normative ethics, meaning what is right or not is laid down through given principles. Religious narratives can also reflect simply the nature of religious experience, so religion is about the way people tell particular stories, or how such stories give structure to the world and try to make sense of it. Narrative can mean more than this, however. It can also mean not just the form in which an encounter with the sacred takes place but also the bearer of the sacred. It can refer to the life story (biography) or experiences of a particular group or individual. Another form of narrative relates to the manner in which biblical text is set forth. Finally, portraying theological issues through narrative implies the use of narrative as a hermeneutic tool (Stroup 1984). I argue here that a greater emphasis on drama is important for ethics from a secular as well as a theological perspective when faced with the grand narrative of the Anthropocene. While I cannot do justice to the full ramifications of this attention to drama in the present context, I seek to give sufficient indicators in order to generate debate and discussion on this issue.

A traditional way of reading history is through genealogies or through a systemization of the dynamics of historical change in various sorts of grand narratives (Lovelock 1987, 2006; Swimme and Berry 1992). This is also true of "cosmic" history, including that expressed in various grand proposals, such as the cosmic creation story of Thomas Berry and Brian Swimme or the Gaia hypothesis of James Lovelock. For Lovelock the biota as a whole contribute in a vital way to the stability of the planet's life, such that the gaseous composition of the atmosphere and temperature are kept within the boundaries that are suitable for life as we know it. Human players are intimately bound up with this narrative inasmuch as only humans are conscious of what is happening, and for Lovelock this consciousness is in some sense representative for the whole earth (Deane-Drummond 2004). Yet, in spite of such an elevated awareness, as far as the earth is concerned human beings do not seem to contribute to its flourishing. One might even view 
humanity, according to some readings of the Gaia hypothesis, as a cancerous growth on the planet, bent on its destruction. The Anthropocene narrative is on a par with the Gaia hypothesis; it is a grand story about the fate of the earth in an era when humans now dominate. Like Gaia, it started off as a scientific theory, and like Gaia, it is becoming adopted more widely. The difference is that the Anthropocene seems less controversial when compared to a global Gaia hypothesis. In the Anthropocene the portrayal of the earth is more mechanistic, in contrast to the biological model from which Gaia takes its cue. In this respect I part company from Bruno Latour (2013), who, it seems to me, has conflated Gaia with the Anthropocene. ${ }^{2}$

Grand narratives create an aura of determinism, in which what is anticipated seems an almost inevitable trajectory of the story as told so far. For this reason, many historians eschew narrative as inherently teleological. As noted above, grand narratives level out social and cultural differences. The ethical and political implications of such epic readings are clear. If humanity is inevitably caught in a narrative that is of its own making but it is unable to change, forced into a new epoch that seems irreversible, then this will lead to fatalism. Politically, this will mean a shift in emphasis so that pessimism about any positive outcome of human intervention prevails; no action at all will be taken.

In practice, actual political activity is far more complex than this account suggests, in that confidence in the more traditional accounts of science on which the Anthropocene tends to rely overlie more subversive notions of science as represented in an expanded ecological account, such as in Gaian theory. In this case, fueled by dreams of a "good" Anthropocene, the competing narrative is more promethean and far more optimistic about humanity's ability to manage its own affairs, including the problems associated with climate change. ${ }^{3}$ Mitigation and adaptation are viewed as both desirable and possible, such that collective human action is sufficient to counter any dangers or threats to human survival.

In the face of acute global water shortages, the Anthropocene may, indeed, encourage a revolutionary politics that assumes that human beings are inevitably caught up with social, political, and cultural change in such a way that weakens any sense of individual agency. This, ironically in the context of Western thought, amounts to a disassociation of the human as a political being from an understanding of humanity's embeddedness in the natural world, a way of perceiving political life as that constructed both by and for human agents. Perceiving the human in political terms as dissociated from nature has been a dominant strand in the Western history of the politics of nature. Peter Scott argues convincingly against such a view in favor of a postnatural politics. In his view, humanity's embeddedness in the natural world becomes not just an adjunct to human affairs, but a new approach to the political realm that weaves in a deeper understanding of human beings as part of nature, which is itself complex and constituted by unsettled boundaries such as that between the natural and artificial. For Scott (2011), 
"postnatural" does not mean so much leaving behind the natural as it does being aware and conscious of how deeply we are embedded in natural processes. The term is also intended to signify looser boundaries between the artificial and the natural, the human and the nonhuman, and thus challenges the notion of "natural" as a distinct category.

It is important to note that drama does not eclipse all narrative; rather, by giving attention to the lyric understood as individual and specific experience, it ensures that it does not slip into grand narrative or epic mode. Ancient literary criticism argued about the extent to which drama as a genre contained narrative, or whether drama imported narrative accounts as it were from the outside. Philodesmus, for example, argued against the position of Aristotle, who, in the Poetics, distinguished epic clearly from tragedy, calling the former narrative, or apangelia. ${ }^{4}$ Yet the figure of the messenger (angelia) in Greek tragedy allows drama to express the narrative voice in a way that closely resembles an epic account. Hence the mix is present in the drama, but narrative is mediated through the messenger. But what precisely is the difference between epic narratives and drama?

Drama is most commonly represented as that which displays human actions and temporal events in specific social contexts. Drama reflects the indeterminacy typical of human life, including the unforeseeable interactions of circumstances and the ambiguities of existence (Balthasar 1988, 17). I suggest that focusing on a local river system and its specific instances of human-natural interactions can move the ethical discussion toward a dramatic approach. Rivers of the Anthropocene is, therefore, in a paradoxical way articulating both a narrative and a drama. It is a grand narrative of the global wedded to the specifics of the drama of the local. But I suggest that there are important religious and ethical consequences of each way of perceiving. Drama also has the characteristic of an "event" through the dynamic staging of particulars in a particular way. It also has an irreducibly social dimension, including the audience as much as those taking part in the play. In addition, drama includes the idea of anticipation, but this is not the same as resignation; rather, it is ongoing, consuming involvement in the work of interpretation (Quash 2005, 35-37). Drama certainly has the capacity to take up narrative elements, as is in evidence in classical Greek tragedy, but the difference from epic is striking, so that "Greek tragedy confronts the spectator directly with a multitude of voices, each with an equal claim, in principle, to truth and authority. The absence of a narrator renders all speech on stage equally authoritative or suspect, equally bound by its status as a rhetorical creation" (Barrett 2002: xvi). These encounters of different voices produce both opacity and ambiguity in language, and to some extent reproduce what occurred in the ancient political arena of Athens. ${ }^{5}$

The political implications of such a move toward the dramatic are, I believe, highly significant. In the place of resignation fostered by the Anthropocene grand narrative there is a greater stress on the importance of individual human agency, or at least agency in the context of a specified community. Yet because such agency 
is one that is caught up in a drama, it does not collapse into either individual liberalism or collective political liberalism but invites what might be called a version of postnatural politics, one where the human and nonhuman creatures are embedded and woven together in a drama. Collective and communitarian action is one, therefore, that is inclusive rather than exclusive of the nonhuman realm. Here one might envision river systems as being much more than simply a stage on which human activity is played out, since it is responsive to the multiple activities of all the different agents in the play. Yet I would press against the idea that the earth as a whole has agency in such a drama; rather, other players are all those creatures or perhaps specific elemental forces within the overall earth system that exist in active relationship with human beings and other agents. While humanity will be aware of its role in such a drama and animals will have a greater power of purposive motion compared to, for example, plants, much will be hidden from view, because the way the drama unfolds will not be known from its beginning, middle, or end.

Close attention to local issues at the human scale in river systems opens up a particular way of discerning that gives significance to individual human agency. The language of practical wisdom, or prudence, gives particular ethical insights into how humans might act in difficult situations in which there are conflicts of interests. It does this through drawing on the classic tradition of community discernment that entails a combined approach, including memoria, or memory of the past, that is authentic, docilitas, or teachability, circumspection, or taking account of concrete situations, including the science, insight, and foresight, as well as caution, that can be broadly related to the secular concept of the precautionary principle. Practical wisdom was developed in the ancient classical world through Aristotelian metaphysics. Aristotle's work was elaborated by Thomas Aquinas, who combined philosophical insights with a theological perspective that included the idea of divinely infused virtues that he drew from Augustine of Hippo. This ancient approach to practical wisdom, combining discernment, judgment, and action, resonates with the preference for the dramatic that I have indicated as important. Further, by including other players in the drama, the process of deliberation can include paying attention to other creatures and their desire for flourishing, as well as limiting a perspective based on a narrow definition of what the good might entail in purely humanistic terms.

How might prudence work when the problems associated with water governance are, in business parlance, sometimes thought of as "wicked"; that is, they lack consensus, are highly complex, and do not seem to be solvable (Camillus 2008: 99-106)? I suggest that while such complex problems may appear to be insoluble there is little excuse for inactivity, because attempts at a better resolution are ways of testing workable alternatives. So the exercise of practical wisdom is still open to risk, but it is a risk that has to be taken. Timothy Carter and Mary Miss hint at this when they suggest the importance of being proactive in the local context of 
urban ecology rather than simply reactive after a disaster (chap. 11, this vol.). Helen Berry also suggests that historical responses to the flooding of the Tyne River in 1771 bring to the surface important lessons in how to anticipate social unrest in times of natural disaster by looking closely at micro-histories-I would like to term these "dramas" - where exercise of prudential reasoning worked across political and social divides (chap. 9, this vol.). Further, once a religious dimension is introduced, as shown historically in Berry's account, the dynamics of the local drama shift to include religious belief in God, a theo-drama. ${ }^{6}$ Religious dynamics, for good or ill, have shaped human entanglement with the natural world in terms of its history, productivity, and impact, including especially the entangled history of humans and riverine systems. As Philip Scarpino points out, the mounting evidence of unintended consequences of human activity are written into the earth's history (chap. 8, this vol.). These are haunting reminders of the human inability to act with prudence. Yet becoming aware of our place in the drama as participants and not mere observers is, perhaps, the first step.

\section{ACKNOWLEDGMENTS}

I am grateful for the invitation to join the Rivers of the Anthropocene project and to the conference participants for helpful discussion and feedback on material presented that formed the basis for this chapter.

\section{NOTES}

1. I define ethics as a reasoned study of how humans act in a given society. It is, at its core, evaluative about what is right or wrong. This distinguishes it from a field such as history, which considers why humans act historically-ostensibly avoiding any judgment of right or wrong. Related to ethics is the issue of morality. I am defining morality as the presupposed or the self-conscious understanding in a given culture of what is the right thing to do. Morality, in its turn, is shaped by the particular way humans tell stories or narratives. Thus there is a relationship between making narratives and the construction of morality within a given culture.

2. See especially Bruno Latour, Lecture 3, "The Puzzling Face of Secular Gaia," and Lecture 4, "Anthropocene and Destruction."

3. For a discussion of the ethical ramifications of very different portrayals of the Anthropocene as "good" and "bad," see in particular Antonaccio 2017.

4. Aristotle, Poetics, 144 9b11, cited in Halliwell 1986, 128-29.

5. The figure of the messenger allowed for implicit claims to a more secure form of knowledge, such that his report presented itself as an unproblematic and nonrhetorical account of events offstage. The figure also allowed for some narration of events that could not easily be presented in a play, such as miracles (de Jong 1991, 117).

6. I develop a theological anthropology that develops the significance of theo-drama for human action in Deane-Drummond 2014. 